Research Article

\title{
Horizontal Subzone Characteristics and Methane Seepage Properties of the Gas Flowing Fracture Zone above the Gob
}

\author{
Wei Qin (iD) and Jialin Xu (1D \\ State Key Laboratory of Coal Resources and Mine Safety, School of Mines, China University of Mining and Technology, Xuzhou, \\ Jiangsu 221116, China
}

Correspondence should be addressed to Jialin Xu; xujlcumt@163.com

Received 11 April 2018; Revised 2 June 2018; Accepted 10 June 2018; Published 1 August 2018

Academic Editor: Dengke Wang

Copyright (C) 2018 Wei Qin and Jialin Xu. This is an open access article distributed under the Creative Commons Attribution License, which permits unrestricted use, distribution, and reproduction in any medium, provided the original work is properly cited.

\begin{abstract}
Gas flowing fracture zone (GFFZ) is an active zone in the gob where pressure-relieved methane can move freely. However, there are very few research findings on the horizontal development characteristics and internal methane seepage properties of GFFZs. In this paper, based on the development height of a GFFZ above the gob, the GFFZ was horizontally divided into the following: a lateral fracture subzone, an O-ring fracture subzone, and a compacted subzone. The identification criteria for all of these horizontal subzones were given by analyzing the influence of the stress in the coal rock mass on the development of mininginduced fractures. A numerical simulation study was conducted to determine the influences of the mining height and mining depth on the morphological development of all horizontal subzones of the GFFZ, and the simulation results showed that the mining height was the main factor influencing the development characteristics of horizontal subzones of the GFFZ. Both the maximum distance of the lateral fracture subzone beyond the mining boundary and the width of the O-ring fracture subzone increased with the increase of mining height. A physical simulation experiment was performed for extraction of gob methane through a surface borehole, and the experimental results showed that the gas flow state was laminar within the range of the lateral fracture subzone and the compacted subzone but that the gas flow state was turbulent, not following Darcy's law, within the range of the O-ring fracture subzone.
\end{abstract}

\section{Introduction}

After a coal seam is mined, the equilibrium state of the in situ stress field is destabilized, the overlying rock is deformed and broken, primary and secondary fractures are developed, and so pressure relief occurs and permeability increases; this provides the route and channel for methane movement, creating conditions for methane extraction. According to the pressure relief, desorption, and movement characteristics of methane, overlying coal rock above the gob is divided the into a gas flowing fracture zone (GFFZ), a pressure relief and desorption zone (PRDZ), and an uneasy desorption zone (UDZ) $[1,2]$, as shown in Figure 1. These zones are described as follows:

(1) GFFZ: Vertical penetrative fractures are present. Relatively full pressure relief and desorption of methane occur within this zone. Methane can rush into the working face along the mining-induced crack-fracture system. Gas movement occurs mainly through free flowing along large cracks and seepage along small fractures. The height of the GFFZ is equal to that of the water flowing fracture zone (WFFZ).

(2) PRDZ: Vertical fractures are not developed. This zone is dominated by tensile fractures along the coal seam. With the transfer of mining-induced stress, methane within the PRDZ is relieved and desorbed to a certain extent and could flow along the coal seam, but little or no gas could rush down to the working face. Gas movement mainly occurs via seepage along the fracture system. The maximum development height of the PRDZ is up to the bottom 


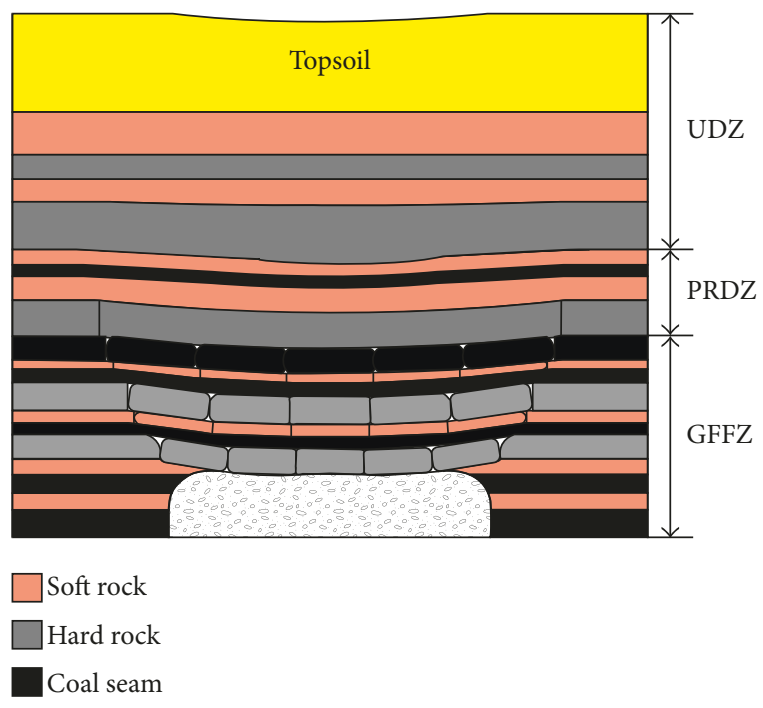

FIGURE 1: The overlying three zones for pressure relief, movement, and extraction of methane in mining of a coal seam group.

of the primary key stratum. With compaction of the coal rock in the PRDZ, the desorbed methane is adsorbed again.

(3) UDZ: There are no mining-induced fractures formed in this zone. The change in the degree of stress in the overlying rock resulting from mining is insufficient to cause desorption of methane, and the occurrence characteristics of methane basically remain unchanged.

At present, research on the horizontal development characteristics of the GFFZ and the methane seepage laws in the GFFZ by scholars from China and other countries remains relatively limited. For example, Palchik described the area that has connection with mine workings as an interconnected fracture zone [3]. Computational fluid dynamics simulations based on site measurement data from either the tube bundle system or tracer tests can provide detailed information for studying goaf gas flow patterns $[4,5]$. Palchik conducted a direct measurement of methane emission from various sections of a borehole to localize horizontal fractures [6]. In the 1990s, Qian and Xu studied the distribution characteristics of mining-induced fractures in the overlying rock strata, proposed an O-ring theory for the distribution of mining-induced fractures, and successfully applied their theory to the layout optimization of boreholes for extraction of pressure-relieved methane in the Taoyuan Coal Mine and the Luling Coal Mine in China [7].

In this paper, identification criteria for horizontal subzones above the gob are given by analyzing the influence of variation in stress in the coal rock mass on the development of mining-induced fractures. A numerical simulation study was conducted to determine how the mining height and mining depth influence the morphological development of the horizontal subzones based on the above criteria. A physical simulation experimental study was performed with a self-developed simulation experimental system for gob methane extraction to disclose the gas seepage laws in all subzones of the GFFZ. These research results could provide theoretical guidance for simultaneous extraction of coal and methane.

\section{Height of the Gas Flowing Fracture Zone}

With vertical broken fractures developed, the GFFZ has a relatively high permeability, and the coal seam methane within the GFFZ is fully relieved and desorbed. The GFFZ has characteristics identical to those of a traditional water flowing fracture zone, and both the gas flowing fracture zone and the water flowing fracture zone have vertical penetrative fractures allowing fluid to flow upward and downward. Therefore, identification of the height of the GFFZ can be obtained by identifying the height of the water flowing fracture zone.

The hard rock strata, which have controlling effects on the movement of overlying rock strata, are called key strata. A hard rock stratum that has a controlling effect on a group of rock strata is called a subkey stratum, and a hard rock stratum that has a controlling effect on its upper layer through surface strata is called a primary key stratum $[8,9]$. Zhu et al. indicated that the position of a primary key stratum has a significant influence on the height of the water flowing fracture zone [10]; when the distance between the primary key stratum and the coal seam is $\langle(7-10) M$ (where $M$ is the mining height), the broken cracks in the primary key stratum will run through to become water flowing fractures, and the water flowing fracture zone would be developed at the bedrock top. When the distance between the subkey stratum and the coal seam is $<(7-10) M$, the broken cracks in the subkey stratum will run through to become water flowing fractures, the broken cracks in the overlying rock strata, which were broken synchronously under the control of this subkey stratum, would also run through to become water flowing fractures, and the water flowing fractures would be developed to the nearest bottom of the subkey stratum above the critical height of $(7-10) M$.

Figure 2 shows how the key stratum position can be used to identify the height of the water flowing fracture zone. The steps are as follows:

Step 1. Collect borehole column data from the working face.

Step 2. Identify the position of the key stratum of overlying rock under the specific borehole column conditions using the key stratum identification software KSPB.

Step 3. Calculate the height from the position of the key stratum to the mined coal seam, and identify whether the broken cracks in the key stratum are penetrative. If the height from the position of the key stratum to the mined coal seam is $>(7-10) M$, the broken cracks in this key stratum are not penetrative; if it is $<(7-10) M$, the broken cracks in this key stratum are penetrative, and the broken cracks in the overlying rock stratum controlled by the key stratum are also penetrative. 


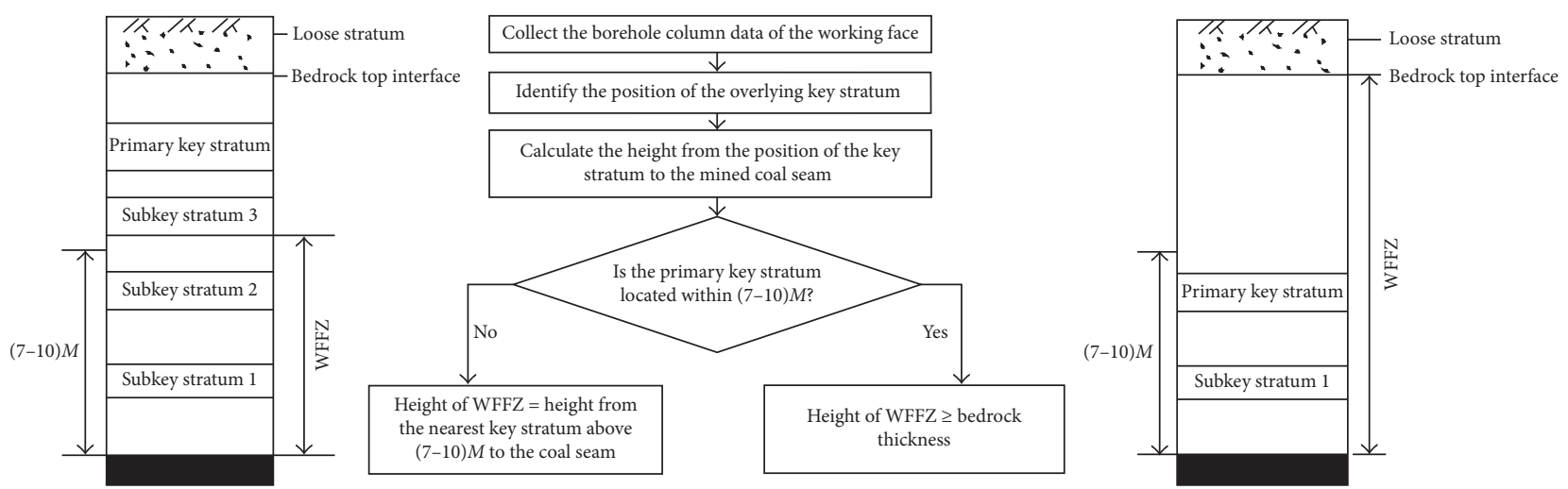

Figure 2: Prediction method flow chart for determining the height of the water flowing fracture zone based on the position of the key stratum.

Step 4. Determine the height of the water flowing fracture zone. When the overlying primary key stratum is located within the critical height $(7-10) M$, water flowing fractures will be developed at the bedrock top, and the height of the water flowing fracture zone will be greater than or equal to the bedrock height; when the overlying primary key stratum is located beyond the critical height $(7-10) M$, water flowing fractures will be developed at the bottom of the nearest subkey stratum above the critical height $(7-10) M$, and the height of the water flowing fracture zone will be equal to the height from this key stratum to the mined coal seam.

In this paper, the height of the GFFZ above the gob is identified using the above identification method for the height of the water flowing fracture zone based on the key stratum position.

\section{Horizontal Subzones of the GFFZ above the Gob}

3.1. Horizontal Subzones. Based on the development laws and morphological characteristics of gas flowing fractures in different areas, the GFFZ above the gob was horizontally divided into the following subzones: (I) lateral fracture subzone, (II) O-ring fracture subzone, and (III) compacted subzone (Figure 3). These subzones are described as follows.

3.1.1. Subzone I. Lateral fracture subzone: After the coal seam is mined, the overlying coal rock stratum gets broken along the breaking line; according to the theory of an elastic foundation beam, the overlying rock stratum breaking line is located at a certain distance from the mining boundary. In addition, the coal rock masses beyond the breaking line are destroyed because of the decrease of horizontal stress, and large quantities of secondary fractures are generated in the coal rock masses under the effect of concentrated stress, greatly increasing the permeability of the coal rock masses; therefore, there exists a lateral fracture subzone with relatively developed fractures in a certain range beyond the mining boundary.

3.1.2. Subzone II. O-ring fracture subzone: This subzone is the $\mathrm{O}$-ring range of mining-induced fractures, delamination fractures, and vertical broken fractures developed in this subzone, and the coal rock masses have relatively high permeability. Therefore, mastering the morphological development characteristics in this subzone has great significance for gob methane extraction.

3.1.3. Subzone III. Compacted subzone: With the constant advance of the mining working face, the overlying rock above the middle of the gob subsides, the broken and caved coal rock masses get compacted, and the mining-induced fractures inside the compacted subzone reclose; thus, the coal rock masses in this subzone have relatively low permeability.

\subsection{Subzone Identification Index}

3.2.1. Influence of the Variation in Stress in the Coal Rock Mass on Development of Mining-Induced Fractures. During mining of a coal seam, the variation in stress in a coal rock mass significantly influences the deformation and failure characteristics of the coal rock mass itself. Figure 4 shows how the variation of the stress field influences the distribution of mining-induced fractures after mining of the coal seam. For the lateral fracture subzone, after the overlying coal rock above the gob is broken, the horizontal stress in the coal rock masses beyond the breaking line decreases significantly; meanwhile, under the effect of lateral abutment pressure, plastic failure occurs in the coal rock masses, significantly raising the permeability of the coal masses. For the O-ring fracture subzone, the vertical stress in the coal rock mass near the coal wall decreases under the supporting effect of the coal wall, delamination fractures can still be maintained continuously, and the permeability is relatively high. Owing to the subsidence of the overlying coal rock, the vertical stress above the middle of the gob reverts to its in situ stress state, the broken and caved coal rock is compacted, mining-induced fractures are closed, and permeability decreases. It can be discerned from the above analysis that the variation of the stress field in the coal rock mass was the intrinsic cause for the formation and development of fractures in the coal rock mass; therefore, the 


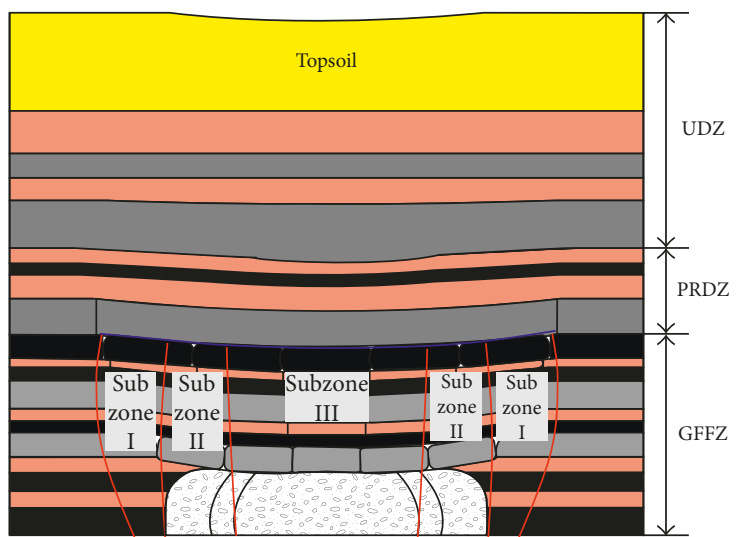

Soft rock

Hard rock

Coal seam

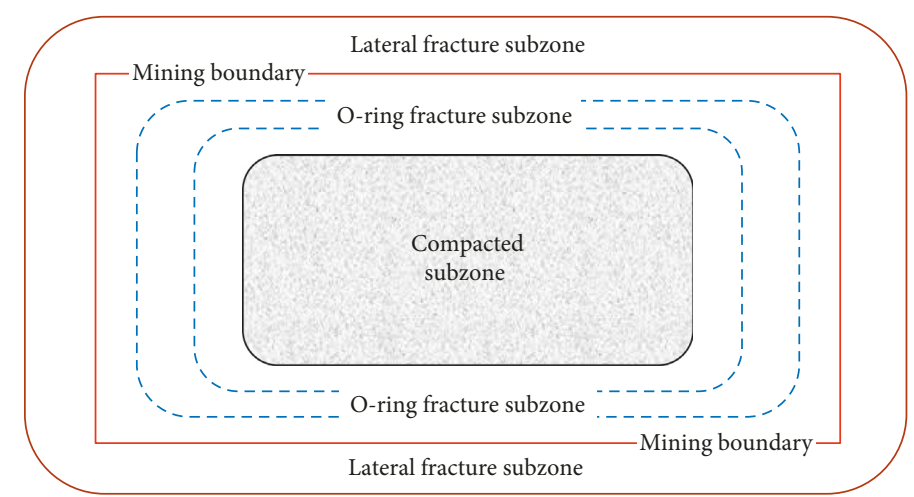

(b)

FIgURE 3: Horizontal subzones of a GFFZ above the gob: (a) vertical profile; (b) horizontal profile.

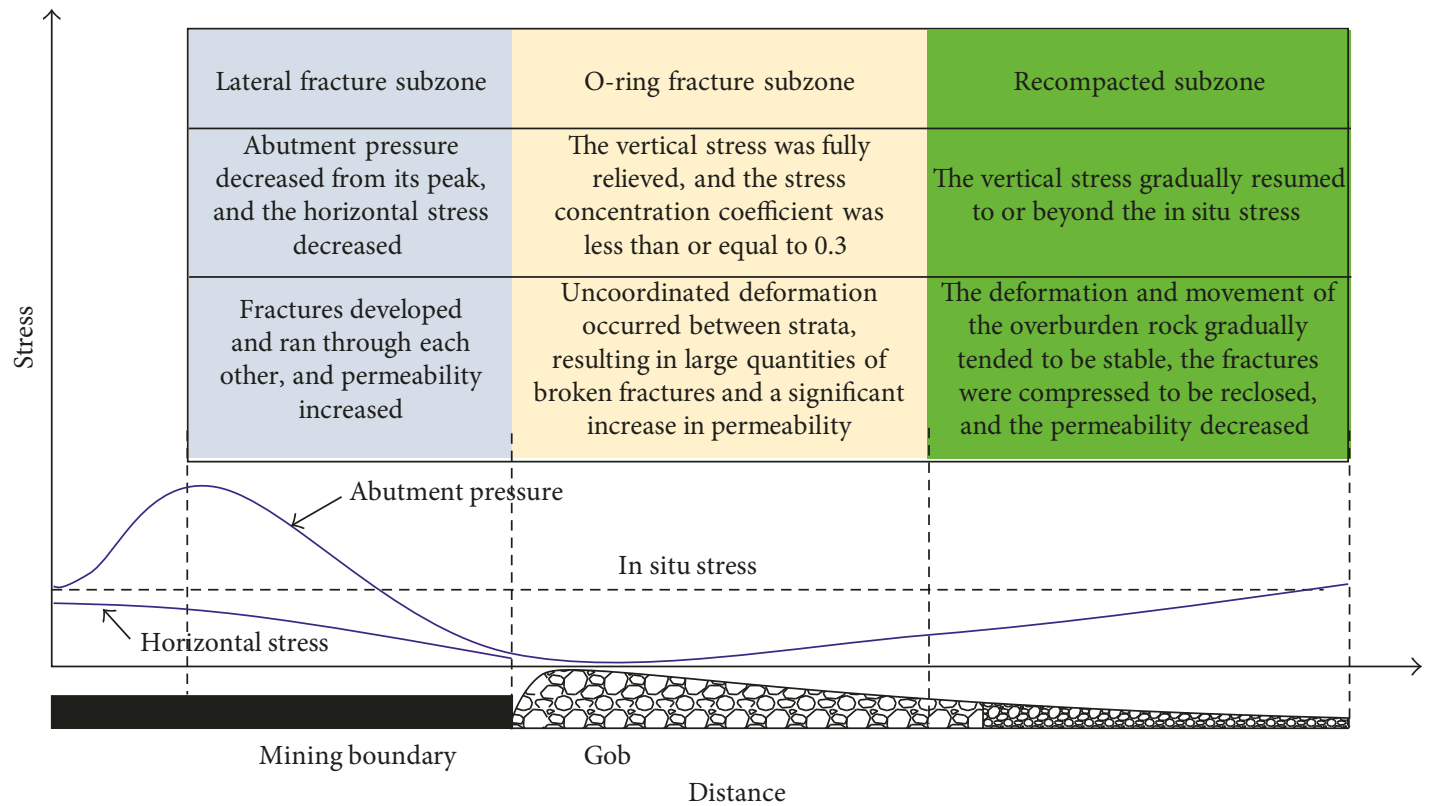

FIGURE 4: Influence of the variation in stress in coal rock masses on the development of mining-induced fractures.

stress distribution characteristics in coal rock masses after mining of a coal seam can be used as identification criteria for the horizontal subzones of the GFFZ used in this paper.

3.2.2. Identification Index for the Horizontal Subzone. Figure 5 shows the distribution of vertical stress and mininginduced fractures in the overlying rock strata of the mining site after the mining of a coal seam [11]. As can be seen from Figure 5, there are basically no mining-induced fractures formed outside the peak of the lateral abutment pressure, whereas there are large quantities of mining-induced fractures distributed inside the peak of the lateral abutment pressure. This can be explained as follows: inside the peak of the lateral abutment pressure, plastic failure occurs in the coal rock masses, and the fractures in the coal rock masses developed and ran through. Therefore, the position of the peak of the lateral abutment pressure can be used as the identification criterion for the outer boundary of the lateral fracture subzone.

$\mathrm{Qu}$ indicated that the degree of pressure relief $r=0.3$ (the ratio of the vertical stress in coal after pressure relief to the original value) was used as the identification criterion for the boundary of the O-ring fracture subzone, based on the constitutive model of rock with primary crack deformation during triaxial pressure relief [12]. It can be seen from 


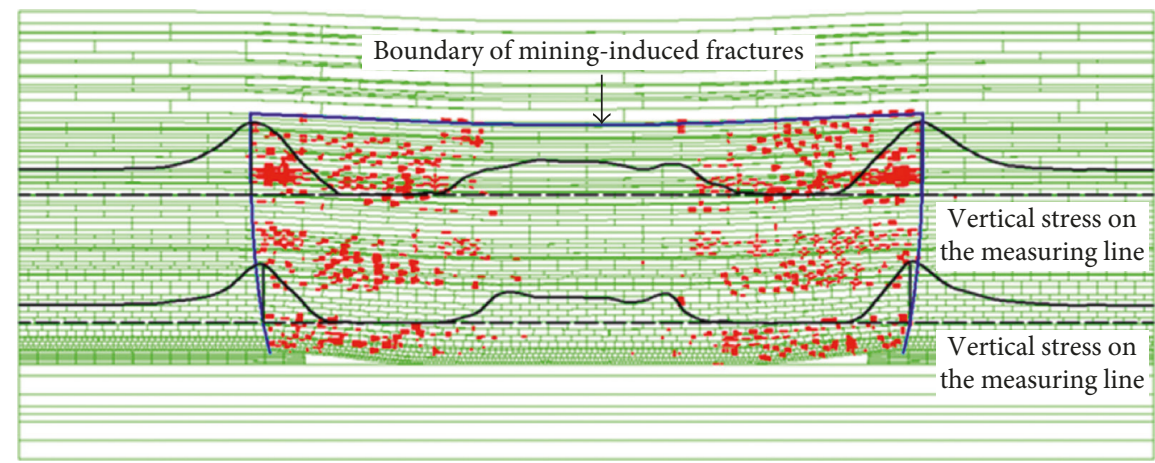

FIgURE 5: Distribution of vertical stress and mining-induced fractures after mining of a coal seam.

Figure 5 that, in the middle of the gob, when the vertical stress rose to $30 \%$ of the in situ stress, the mining-induced fractures basically disappeared.

\section{Factors Influencing Morphological Development of Horizontal Subzones}

At present, scholars from China and other countries have made great strides in quantitatively studying the height of the GFFZ, but studies on the factors influencing the morphological development of the horizontal subzones of the GFFZ are lacking. Consequently, in this paper, a numerical calculation model for dip direction was established based on the production geological conditions at the K8206 fully mechanized working face (FMWF K8206) in Yangquan Coal Mine no. 3 using the Universal Distinct Element Code (UDEC) numerical simulation software, and a numerical simulation study was conducted to determine the influences of the mining height and mining depth of the working face on the morphological development of the horizontal subzones of the GFFZ.

4.1. Brief Introduction to UDEC. UDEC is a twodimensional numerical software that simulates the quasistatic or dynamic response to loading of media containing multiple, intersecting joint structures. The discontinuous medium is represented as an assemblage of discrete blocks, while the discontinuities are treated as boundary conditions between blocks. Large displacements along discontinuities and rotations of blocks can occur. UDEC utilizes an explicit solution scheme that can model complex, nonlinear behaviours [13].

4.2. Production Geological Conditions at the Working Face. FMWF K8206 is the working face for mining \#15 coal seam in Yangquan Coal Mine no. 3. Its elevation is 503.6-596.3 m; the elevation of the ground surface is $1025-1168 \mathrm{~m}$; and the working face has a strike length of $1579 \mathrm{~m}$, a dip length of $252.2 \mathrm{~m}$, and an average advance speed of $3 \mathrm{~m} / \mathrm{d}$. For the working face, the coal seam has a total thickness of $6.8 \mathrm{~m}$ and a net coal thickness of $6.8 \mathrm{~m}$, and it dips $1^{\circ}-7^{\circ}$, averaging $5^{\circ}$. In the coal seam, the original methane content is $7.13 \mathrm{~m}^{3} / t$, and the original methane pressure is $0.20-0.30 \mathrm{MPa}$. The strike longwall retreat mining method and fully mechanized top-coal caving technology have been used for FMWF $\mathrm{K} 8206$, and the roof is managed using the fully caving method.

Based on the geological borehole column at FMWF K8206, the positions of the key strata at the fully mechanized working face were identified by using the key stratum identification software $\mathrm{KSPB}$; the results are shown in Figure 6. As can be discerned from the figure, there are five subkey strata and one primary key stratum existing in the overlying rock strata above FMWF K8206. The distance from the primary key stratum to the mined coal seam is $172.6 \mathrm{~m}$. According to the identification method for the height of the water flowing fracture zone based on the position of the key stratum, the height from the position of the key stratum to the mined coal seam is $>(7-10) M$, so water flowing fractures in FMWF K8206 would be developed to the nearest key stratum at heights $>7-10$ greater than the mining height; that is, in subkey stratum 3, it is $125.21 \mathrm{~m}$ from the mined coal seam.

Based on the production geological conditions at FMWF K8206, a 2D numerical model for dip direction was established. The model had a length of $500 \mathrm{~m}$ and a height of $186 \mathrm{~m}$, the coal seam thickness was $7 \mathrm{~m}$, and the working face length was $250 \mathrm{~m}$, with a $125 \mathrm{~m}$ coal pillar left on each side. The upper rock layer with a thickness of $314 \mathrm{~m}$ in the model was converted into a uniform load of $7.85 \mathrm{MPa}$ applied to the top interface of the model. The left and right boundaries of the model were fixed in the horizontal direction, and the bottom boundary was fixed in the vertical direction.

Coal is usually assumed to be an isotropic homogeneous medium, and the commonly used yield criteria mainly include the Mohr-Coulomb yield criterion, the DruckerPrager yield criterion, the Griffith yield criterion, the Hoek-Brown yield criterion, and twin shear strength criterion. Among them, the Mohr-Coulomb yield criterion can well reflect the strength characteristics of geotechnical materials, and its linear characteristics can make the procedures and equations of analytical calculation more concise. Therefore, the material constitutive model used was an ideal elastoplastic constitutive model with a Mohr-Coulomb yield criterion. This model can simulate the influence of mining height and depth on the morphological development of horizontal subzones by enabling the thickness of the coal 


\begin{tabular}{|c|c|c|c|c|c|c|}
\hline & Order & Thickness (m) & Depth (m) & Lithology & Position & \multirow{3}{*}{ 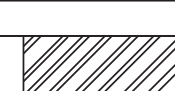 } \\
\hline ב & 53 & 340.34 & 340.34 & Simplified load layer & \multirow{3}{*}{ PKS } & \\
\hline & 52 & 5.98 & 346.32 & Siltstone & & \\
\hline & 51 & 4.39 & 350.71 & Coarse sandstone & & \\
\hline & 50 & 0.98 & 351.69 & Siltstone & & \\
\hline & 49 & 3.33 & 355.02 & Fine sandstone & & \\
\hline & 48 & 6.72 & 361.74 & Siltstone & SKS-5 & $\cdots \cdots . . . \cdots \cdots$ \\
\hline & 47 & 4 & 365.74 & Coarse sandstone & & \\
\hline & 46 & 1.5 & 367.24 & Siltstone & & \\
\hline घ̆ & 45 & 6.79 & 374.03 & Fine sandstone & SKS-4 & ..."...." \\
\hline ఠ & 44 & 1 & 375.03 & Siltstone & & 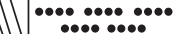 \\
\hline & 43 & 4 & 379.03 & Medium sandstone & & \\
\hline & 42 & 1.81 & 380.84 & Coal seam \#3 & & \\
\hline & 41 & 1.7 & 382.54 & Siltstone & & \\
\hline & 40 & 4.39 & 386.93 & Mudstone & & \\
\hline & 39 & 6.8 & 393.73 & Siltstone & SKS-3 & \\
\hline & 38 & 2.58 & 396.31 & Siltstone & & \\
\hline & 37 & 5.14 & 401.45 & Medium sandstone & &..${ }^{\bullet}$ \\
\hline & 36 & 1.2 & 402.65 & Siltstone & & 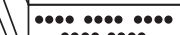 \\
\hline & 35 & 4.6 & 407.25 & Medium sandstone (K7) & & $\ldots$ \\
\hline & 34 & 2.35 & 409.6 & Siltstone & & 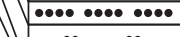 \\
\hline & 33 & 2.67 & 412.27 & Mudstone & & $\ddot{*}$ \\
\hline & 32 & 1.64 & 413.91 & Siltstone & & 6 \\
\hline & 31 & 6.5 & 420.41 & Mudstone & & $\ldots$ \\
\hline & 30 & 3.4 & 423.81 & Mudstone & & E: \\
\hline & 29 & 1.5 & 425.31 & Coal seam \#8 & & \\
\hline & 28 & 2.03 & 427.34 & Mudstone & & \\
\hline & 27 & 1.25 & 428.59 & Mudstone & & \\
\hline & 26 & 2.5 & 431.09 & Fine sandstone & & $E$ \\
\hline & 25 & 6.5 & 437.59 & Coarse sandstone & & $\cdots \cdots$ \\
\hline & 24 & 0.6 & 438.19 & Mudstone & & $\cdot \bullet$ \\
\hline & 23 & 3 & 441.19 & Medium sandstone (K6) & & 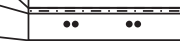 \\
\hline $\overrightarrow{\mathrm{N}}$ & 22 & 11.74 & 452.93 & Siltstone & SKS-2 & $\bullet \bullet \bullet \cdots \cdots \cdots$ \\
\hline in & 21 & 3.4 & 456.33 & Mudstone & & 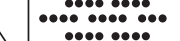 \\
\hline & 20 & 2.36 & 458.69 & Medium sandstone & & 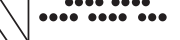 \\
\hline 定 & 19 & 2 & 460.69 & Siltstone & & 椇: \\
\hline & 18 & 3 & 463.69 & Mudstone & & .... \\
\hline & 17 & 2 & 465.69 & Limestone (K4) & & 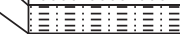 \\
\hline & 16 & 0.2 & 465.89 & Coal seam \#11 & & 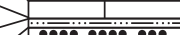 \\
\hline & 15 & 1 & 466.89 & Silty mudstone & & \\
\hline & 14 & 3.2 & 470.09 & Siltstone & & 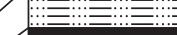 \\
\hline & 13 & 5 & 475.09 & Silty mudstone & & ..• \\
\hline & 12 & 1.71 & 476.8 & Coal seam \#13 & & 1 \\
\hline & 11 & 2.93 & 479.73 & Fine sandstone & & \\
\hline & 10 & 6.6 & 486.33 & Limestone (K3) & & $.{ }^{*} . . \cdot$. \\
\hline & 9 & 16.73 & 503.06 & Medium sandstone & SKS-1 & 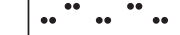 \\
\hline & 8 & 3.4 & 506.46 & Silty mudstone & & 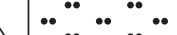 \\
\hline & 7 & 2.82 & 509.28 & Limestone & & 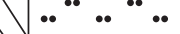 \\
\hline & 6 & 3.01 & 512.29 & Silty mudstone & & 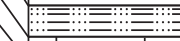 \\
\hline & 5 & 1.11 & 513.4 & Limestone & & 1 \\
\hline & 4 & 3.23 & 516.63 & Siltstone & & \\
\hline & 3 & 2.03 & 518.66 & Limestone (K2) & & 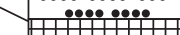 \\
\hline & 2 & 0.28 & 518.94 & Mudstone & & \\
\hline & 1 & 6.8 & 525.74 & Coal seam \#15 & & \\
\hline
\end{tabular}

Figure 6: Identification results of overlying key strata at FMWF K8206.

seam and the top load to be changed. The structural schematic diagram of the model is shown in Figure 7.

Table 1 lists the mechanical parameters of the overlying rock strata above the gob based on the lithologic measurement results of the roof at FMWF K8206.

4.3. Influence of Mining Height on Morphological Development of Horizontal Subzones of the GFFZ. To study the influence of the mining height on the morphological development of horizontal subzones of the GFFZ, numerical calculation models were established for simulation with mining heights of $1,2,3,4,5,6$, and $7 \mathrm{~m}$, respectively, based on the production geological conditions at FMWF K8206. Figure 8 shows the laws of variation of the morphological development of the horizontal subzones of the GFFZ under different mining heights according to the simulation results. 


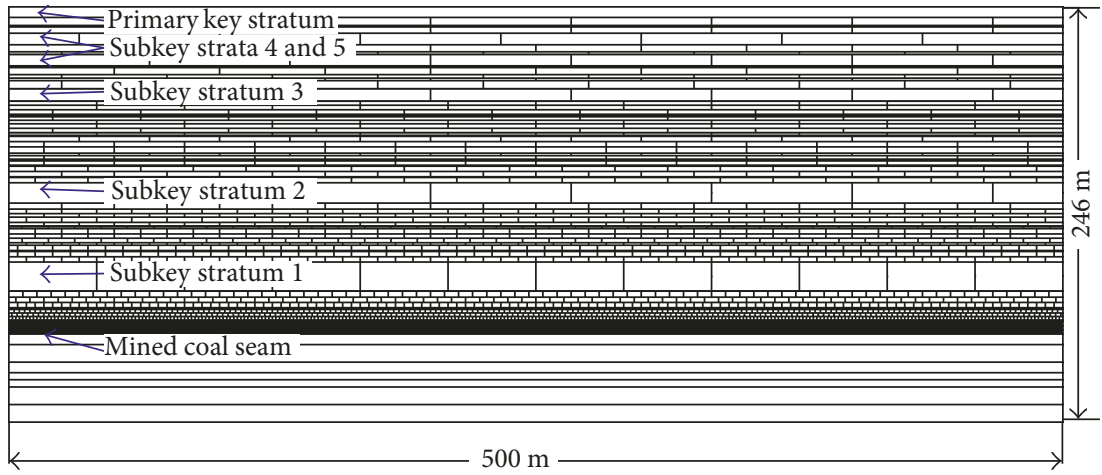

FIgURE 7: Structural schematic diagram of the model.

TABLE 1: Physical and mechanical properties of rock strata.

\begin{tabular}{|c|c|c|c|c|c|c|c|}
\hline Lithology & $\begin{array}{c}\text { Elastic modulus } \\
E(\mathrm{GPa}) \\
\end{array}$ & $\begin{array}{l}\text { Poisson's } \\
\text { ratio } \mu\end{array}$ & $\begin{array}{c}\text { Tensile strength } \\
(\mathrm{MPa})\end{array}$ & $\begin{array}{c}\text { Normal stiffness } \\
\left(\mathrm{GPa} \cdot \mathrm{m}^{-1}\right)\end{array}$ & $\begin{array}{c}\text { Shear stiffness } \\
\left(\mathrm{GPa} \cdot \mathrm{m}^{-1}\right)\end{array}$ & $\begin{array}{c}\text { Internal friction } \\
\text { angle } \varphi\left(\left(^{\circ}\right)\right.\end{array}$ & $\begin{array}{c}\text { Cohesion } C \\
(\mathrm{MPa})\end{array}$ \\
\hline Siltstone & 20.2 & 0.19 & 1.3 & 16.0 & 12.0 & 33.5 & 9.19 \\
\hline $\begin{array}{l}\text { Coarse } \\
\text { sandstone }\end{array}$ & 25.0 & 0.19 & 1.4 & 18.0 & 14.0 & 38.6 & 9.5 \\
\hline $\begin{array}{l}\text { Fine } \\
\text { sandstone }\end{array}$ & 15.0 & 0.20 & 1.5 & 21.0 & 16.0 & 32.5 & 5.5 \\
\hline $\begin{array}{l}\text { Medium } \\
\text { sandstone }\end{array}$ & 35.0 & 0.15 & 1.5 & 20.0 & 16.0 & 38.9 & 10.7 \\
\hline Coal & 2.2 & 0.28 & 1.0 & 5.0 & 3.5 & 36.5 & 2.62 \\
\hline Mudstone & 2.0 & 0.24 & 1.2 & 9.6 & 6.2 & 27 & 2.32 \\
\hline $\begin{array}{l}\text { Sandy } \\
\text { mudstone }\end{array}$ & 1.5 & 0.26 & 1.3 & 7.5 & 4.5 & 30 & 3.43 \\
\hline
\end{tabular}

As can be discerned from Figure 8, variations in the morphology of the lateral fracture subzone were mainly reflected by the variation of the outer boundary of the lateral fracture subzone, and the maximum distance of the lateral fracture subzone beyond the mining boundary increased with the increase of mining height. As a whole, with the increase of mining height, the average width of the O-ring fracture subzone increased gradually; when the mining height increased from 1 to $7 \mathrm{~m}$, the average width of the $\mathrm{O}$-ring fracture subzone increased gradually from a minimum of $22.8 \mathrm{~m}$ to a maximum $57.2 \mathrm{~m}$; the increase gradient in the average width of the O-ring fracture subzone decreased gradually with the increase of mining height. With the increase of mining height, the average width of the compacted subzone decreased gradually; when the mining height increased from 1 to $7 \mathrm{~m}$, the average width of the compacted subzone decreased gradually from a maximum of $184.6 \mathrm{~m}$ to a minimum of $100.1 \mathrm{~m}$.

4.4. Influence of Mining Depth on Morphological Development of Horizontal Subzones of the GFFZ. To study the influence of mining depth on the morphological development of the horizontal subzones of the GFFZ, the morphological development characteristics of the horizontal subzones of the GFFZ were simulated at mining depths of 300, 500, and $700 \mathrm{~m}$ by changing the boundary load based on the production geological conditions at FMWF K8206. The vertical stress on the horizontal measuring line was extracted under the conditions in various schemes, and the laws of variation of the morphological development of the horizontal subzones of the GFFZ were obtained using the boundary identification criteria for the horizontal subzones of the GFFZ, as shown in Figure 9.

As can be discerned from Figure 9, with the increase of mining depth, the outer boundary line of the lateral fracture subzone tended to move away from the mining boundary, which, however, was not very conspicuous. When the mining depth increased from 300 to $700 \mathrm{~m}$, the minimum and maximum distances of the lateral fracture subzone from the mining boundary increased by 1.2 and $2 \mathrm{~m}$, respectively. With the increase of mining depth, the average width of the O-ring fracture subzone decreased gradually. In the process during which the mining depth increased from 300 to $700 \mathrm{~m}$, the average width of the $\mathrm{O}$-ring fracture subzone decreased by $10.6 \mathrm{~m}$. With the increase of mining depth, the average width of the compacted subzone increased gradually. In the process during which the mining depth increased from 300 to $700 \mathrm{~m}$, the average width of the compacted subzone increased gradually by $22.8 \mathrm{~m}$.

\section{Physical Simulation Experiment of Gob Methane Extraction}

5.1. Experimental Apparatus. A self-developed "simulation experimental system for gob methane extraction" (Figure 10) 


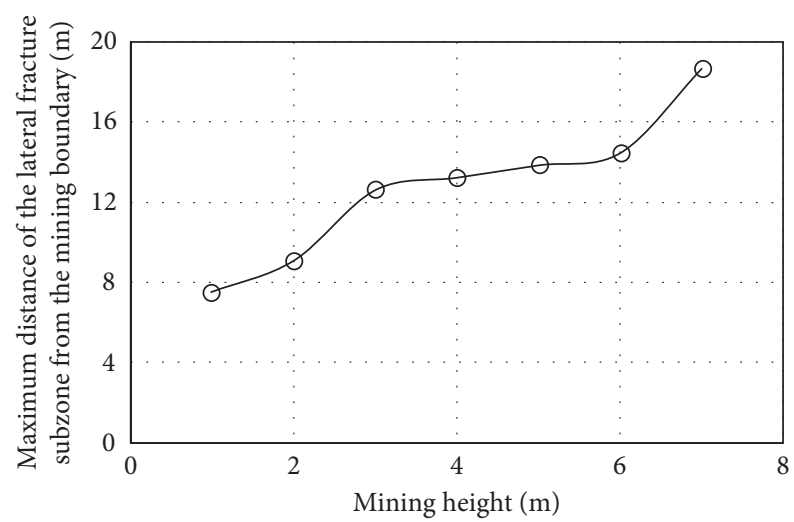

(a)

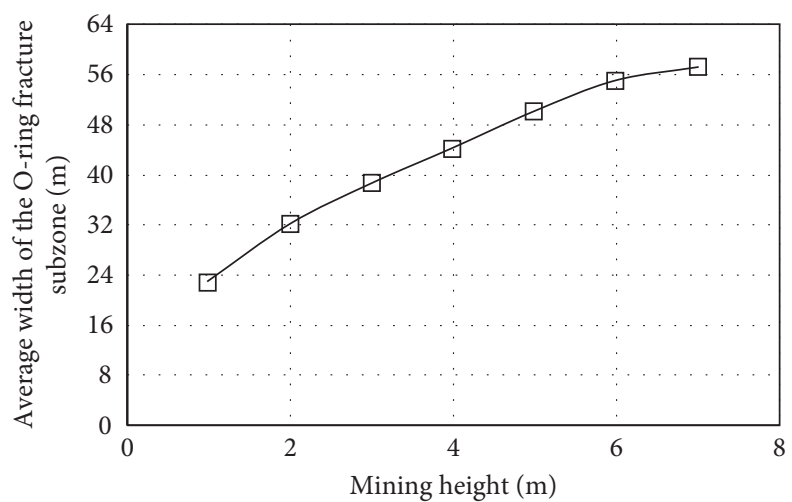

(b)

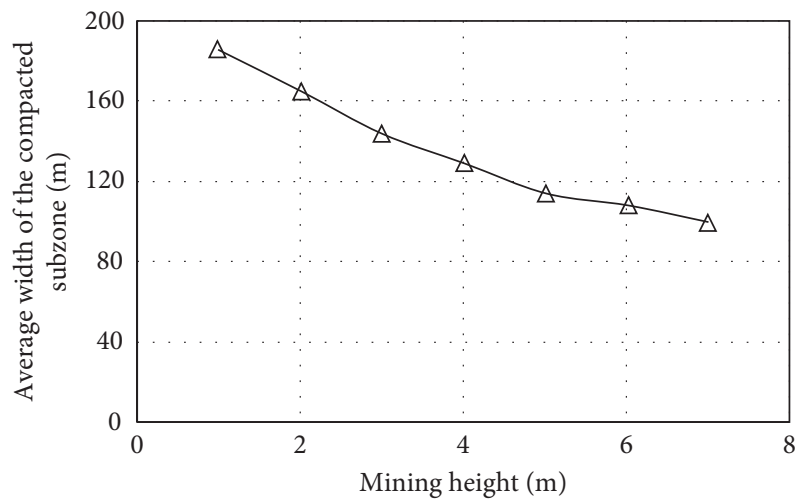

(c)

Figure 8: Laws of variation of the horizontal subzones of the GFFZ under different mining heights: (a) lateral fracture subzone; (b) O-ring fracture subzone; (c) compacted subzone.

was used in this experiment, and the main components of this system included five parts: the main frame and support base, the fan power system, the methane injection system, the mining simulation system, and the monitoring and control system.

The function of all parts in this system is as follows:

(i) The main frame and support base: The size of the main frame is $3.2 \mathrm{~m} \times 1.8 \mathrm{~m} \times 1.8 \mathrm{~m}$, enclosed within acrylic glass and using a sealing washer to ensure that the experimental subject is isolated from the outside air. The size of the support base is $3.3 \mathrm{~m} \times 1.9 \mathrm{~m} \times 1.9 \mathrm{~m}$.

(ii) The fan power system: This provides different suction pressures for the vertical well through the use of small vacuum pumps.

(iii) The methane injection system: This supplies methane at different flow rates, from various sources such as residual coal and adjacent coal seams.

(iv) The mining simulation system: A lifting screw is used to simulate coal seam mining. The caving zone at the bottom of the main frame descends by downward motion of the screw. The mining simulation system can simulate a mining height of $2-10 \mathrm{~m}$. (v) The monitoring and control system: Data from sensors in the monitoring system are converted into electrical signals by the data acquisition module and then sent to the engine control console of the control system, in which software processes and stores the experimental data.

5.2. Experimental Schemes. In this simulation experiment, FMWF K8206 in Yangquan Coal Mine no. 3 was taken as a prototype. Loose masses and prefabricated blocks were used to simulate the overlying rocks of the caving and fracture zones, respectively; the loose masses simulating the caving zone were formed by mixing pebbles with different grain sizes and yellow sand, and the dimensions and laying sequence of the prefabricated blocks simulating the fracture zone depended on the breaking dimensions of the overlying hard rock strata (Figure 11).

The surface borehole was simulated by a metal tube $3 \mathrm{~mm}$ in diameter. In this experiment, the surface borehole was placed $65 \mathrm{~m}$ from the open-off cut. In scheme 1, the surface borehole was located $10 \mathrm{~m}$ beyond the boundary of the gob; based on scheme 1 , the borehole locations in the other schemes were moved $30 \mathrm{~m}$ inwards towards the gob in turn (Figure 12). Under the conditions of scheme 1, the 


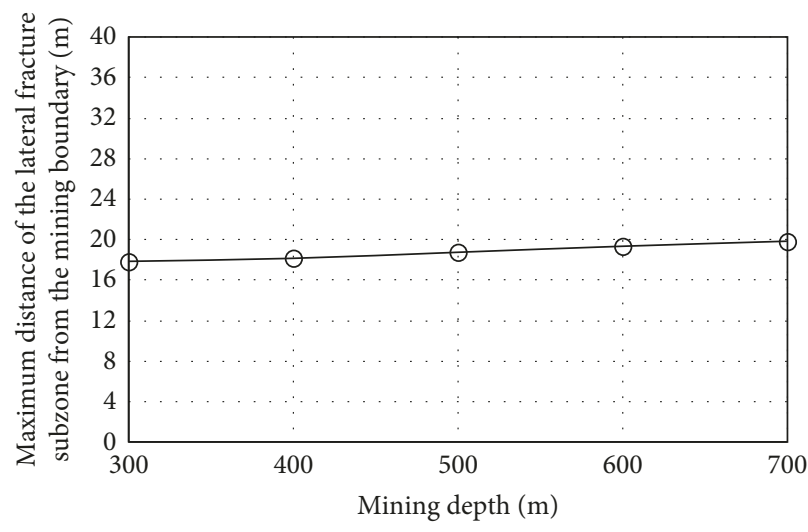

(a)

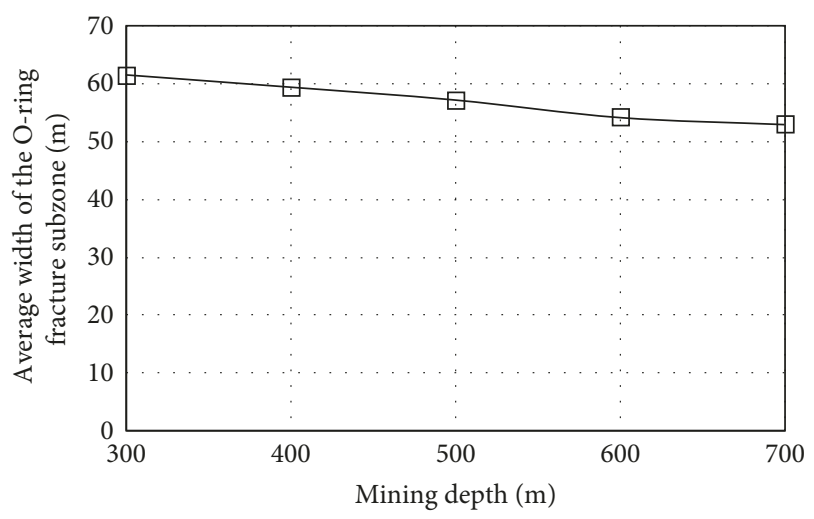

(b)

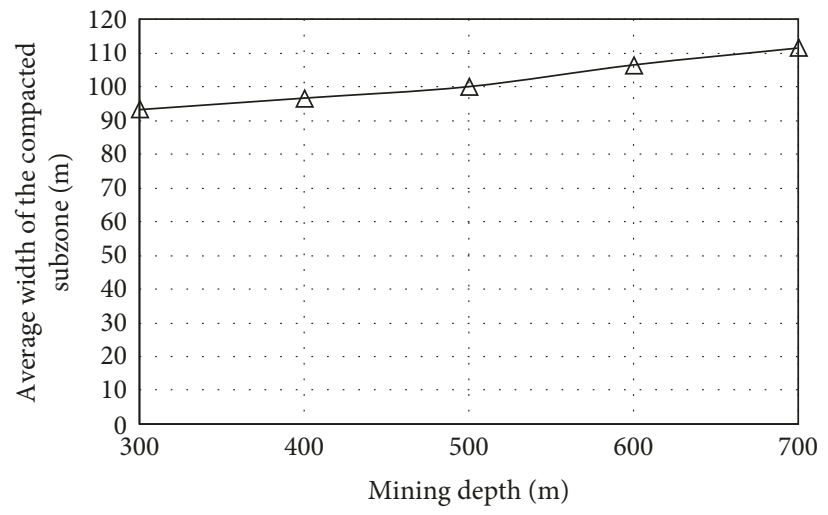

(c)

Figure 9: Laws of variation of the horizontal subzones of the GFFZ under different mining depths: (a) lateral fracture subzone; (b) O-ring fracture subzone; (c) compacted subzone.

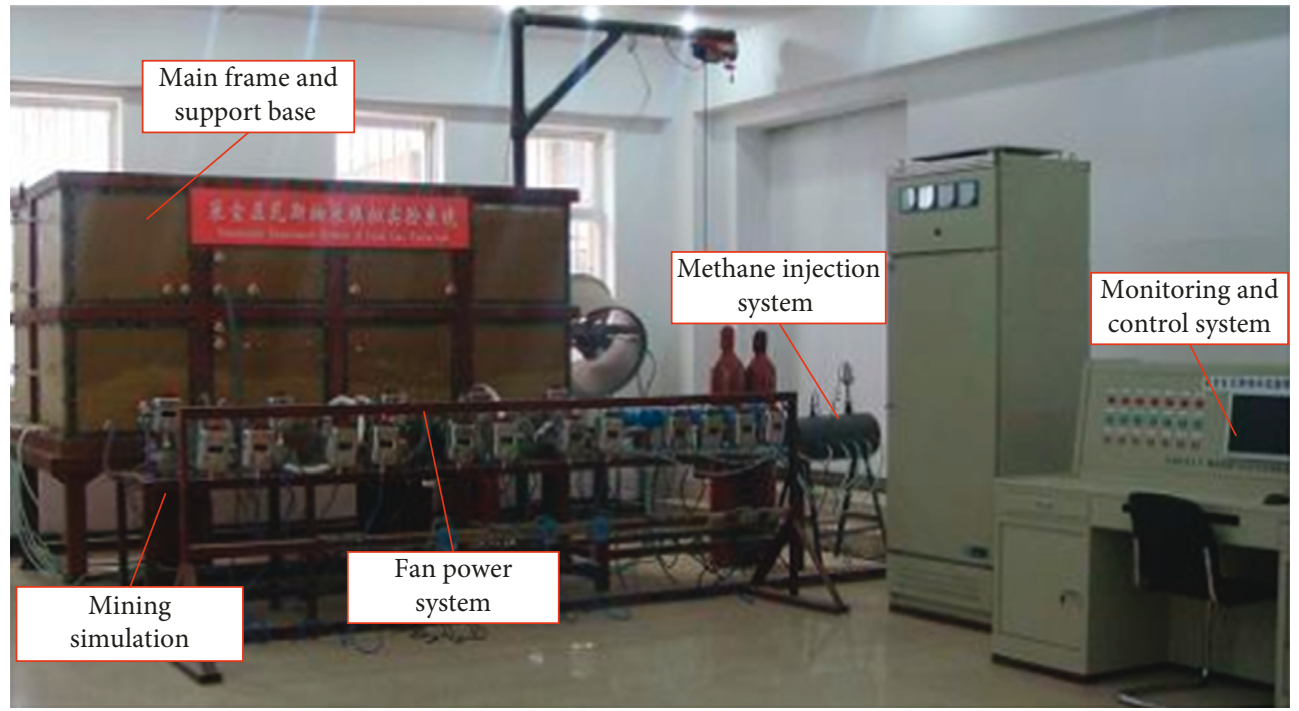

FIGURE 10: Simulation experimental system for gob methane extraction [14, 15].

surface borehole was located within the lateral fracture subzone. Under the conditions of schemes 2 and 3, both surface boreholes were located within the O-ring fracture subzone, where bed-separated fissures developed with high permeability. Under the conditions of cases 4 and 5, both vertical wells were located within the compacted subzone. 


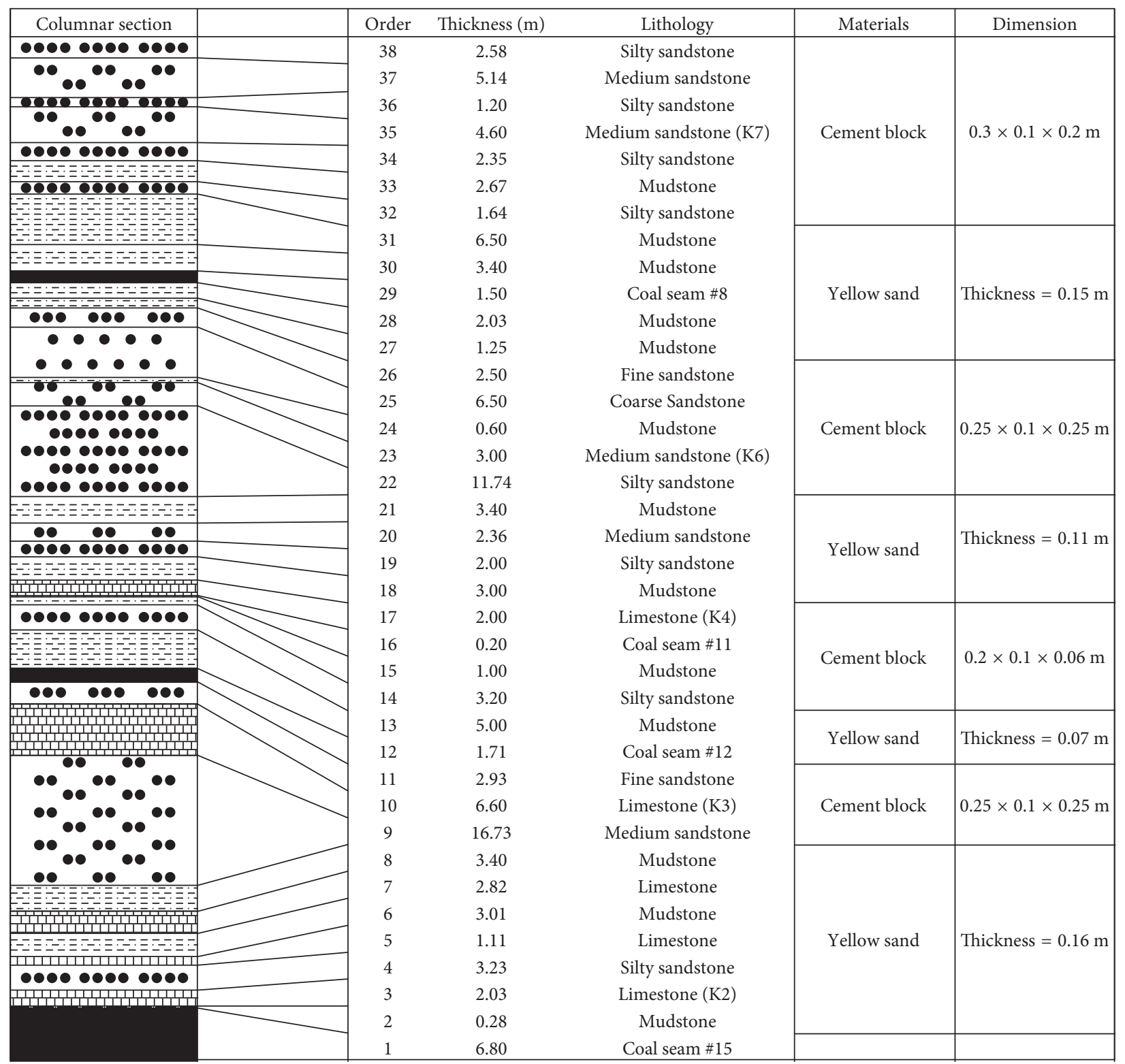

FIgURE 11: Schematic diagram of the trapping foam board and yellow sand.

5.3. Analysis of Experimental Results. Figure 13 shows the curves of the mixture flow rate at initial extraction versus suction pressure for different surface borehole locations. As can be seen from Figure 13, the initial methane flow rate from the borehole increased linearly with suction pressure under the conditions in schemes 1,4 , and 5, indicating that the lateral fracture subzone and compacted subzone had relatively low permeability and that the methane-air mixture gas had a relatively slow flow speed; the gas flow speed and the gas pressure difference had a directly proportional relationship, basically following Darcy's law; and the methane flow state in this zone was laminar. Under the conditions in schemes 2 and 3, with the increase of suction pressure, the initial methane flow rate no longer increased linearly; because the delamination fractures in the O-ring fracture subzone were developed and the gas flow speed was relatively fast, the methane flow state in the O-ring fracture subzone was turbulent under the surface borehole extraction conditions and Darcy's law was no longer applicable.

\section{Conclusions}

Based on the height of a GFFZ above the gob, the GFFZ was divided into the following: a lateral fracture subzone, an O-ring fracture subzone, and a compacted subzone. Identification criteria for the horizontal subzones were given by analyzing the influence of the variation in stress in the coal rock mass on the development of mining-induced fractures: the position of the peak of the lateral abutment pressure was used as the identification criterion for the outer boundary of the lateral fracture subzone, and the degree of stress pressure 


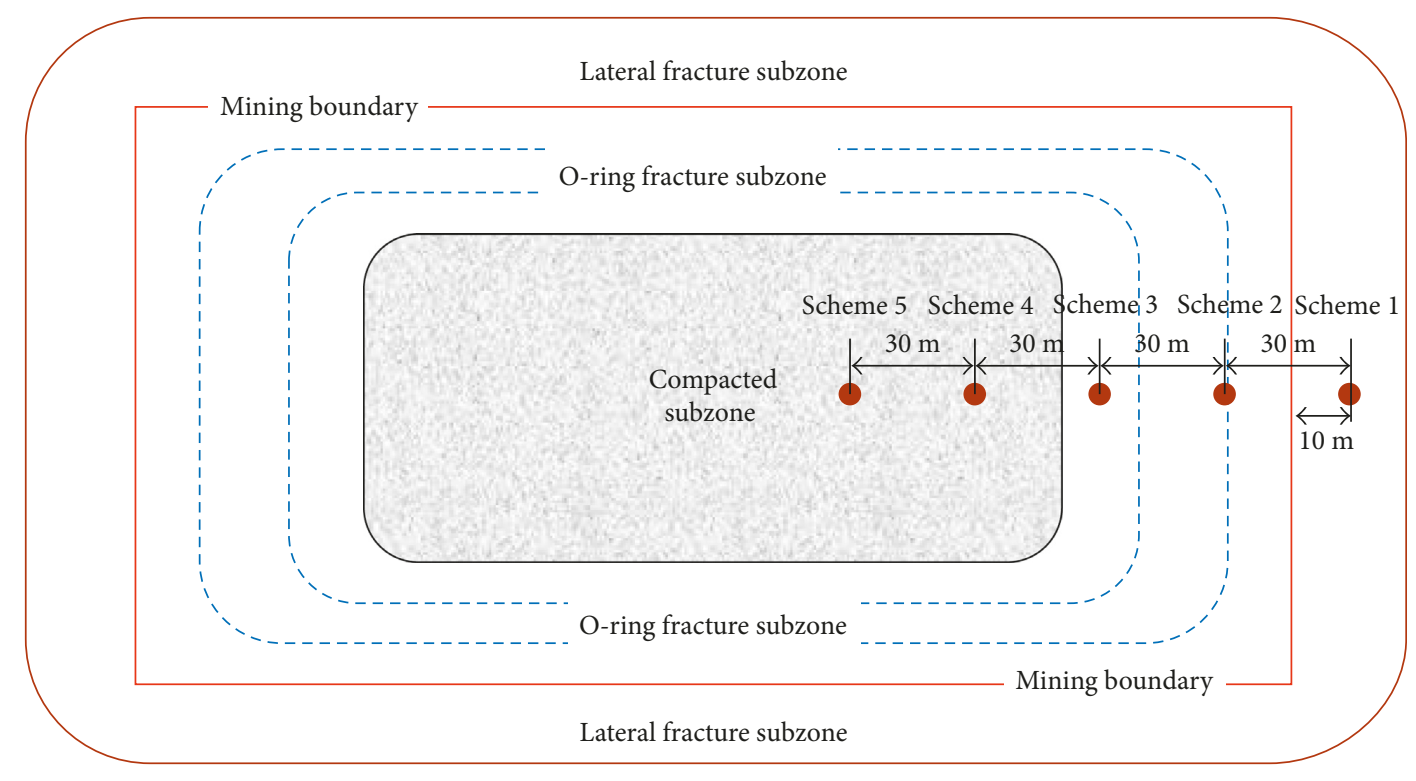

FiguRE 12: Layout schemes for the surface boreholes [15].

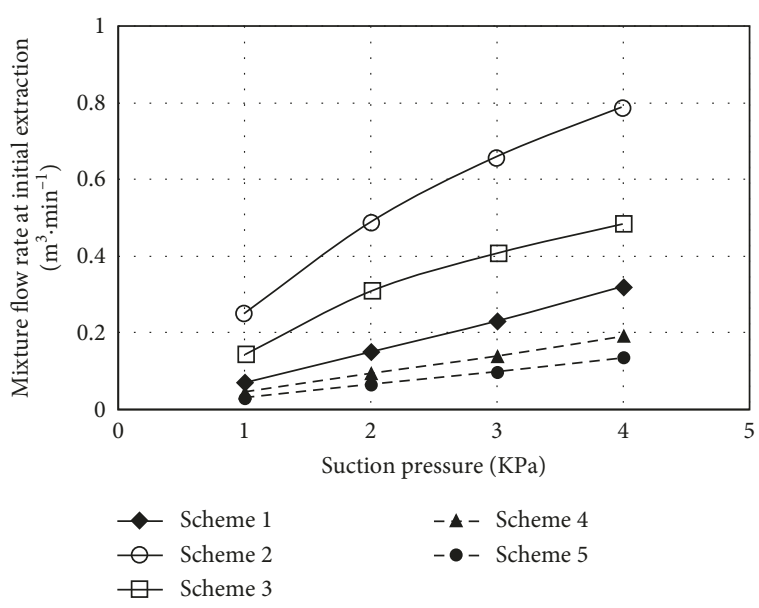

(a)

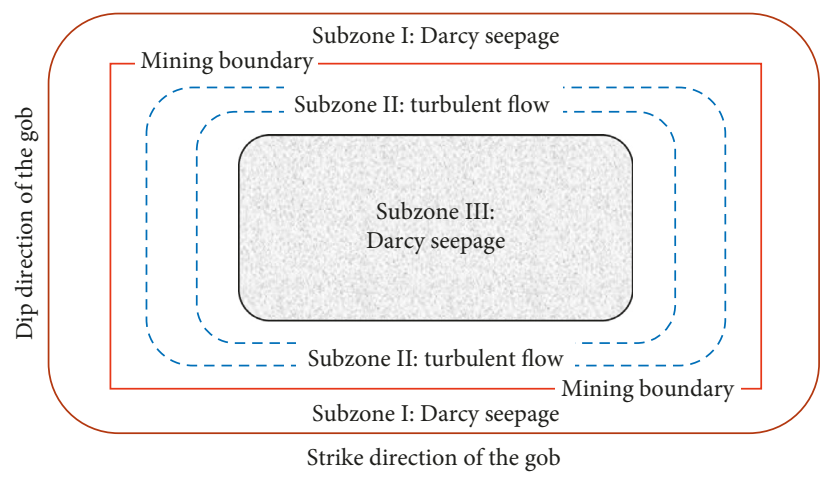

(b)

FIgURE 13: Distribution characteristics of the gas flow state in the gob under surface borehole extraction conditions: (a) mixture flow rate at initial extraction; (b) methane flow state.

relief $r=0.3$ was used as the identification criterion for the boundary of the O-ring fracture subzone.

A numerical simulation study was conducted to ascertain how the mining height and mining depth influenced the development characteristics of the horizontal subzones of the GFFZ. The results showed that the mining height was the main factor influencing the morphological development of horizontal subzones of the GFFZ and that the maximum distance of the lateral fracture subzone from the mining boundary increased stepwise with the increase of mining height. The average width of the O-ring fracture subzone increased gradually with the increase of mining height. In the case of the fixed working face length, the width of the compacted subzone decreased constantly with the increase of mining height.
A physical simulation experiment study on gob methane extraction from surface boreholes was performed with a selfdeveloped simulation experimental system for gob methane extraction, and the simulation results showed that the extraction mixture flow rate from all surface boreholes exhibited a constantly attenuating trend; under the same suction pressure, the methane extraction mixture flow rate from a surface borehole in the O-ring fracture subzone was relatively high, whereas that from a surface borehole in the compacted subzone was relatively low. The methane flow states in different horizontal subzones were analyzed, and the results showed that the methane flow states in the lateral fracture subzone and compacted subzone were laminar but that in the O-ring fracture subzone did not follow Darcy's law and was turbulent. 


\section{Data Availability}

All relevant data are available from Figshare (https:// figshare.com/s/e72c1f8e7c8ed0bcf963).

\section{Conflicts of Interest}

The authors declare that there are no conflicts of interest regarding the publication of this paper.

\section{Acknowledgments}

The authors thank X. Peng for assistance with the experiments and Y. Dong for valuable discussion. Financial support for this work was provided by the Natural Science Foundation of China (no. 51604261), Fundamental Research Funds for the Central Universities (no. 2014QNB39), and Priority Academic Program Development of Jiangsu Higher Education Institutions (no. SZBF2011-6-B35).

\section{References}

[1] Q. D. Qu, J. L. Xu, and R. L. Wu, "Three-zone characterisation of coupled strata and gas behaviour in multi-seam mining," International Journal of Rock Mechanics and Mining Sciences, vol. 78, pp. 91-98, 2015.

[2] Q. D. Qu, H. Guo, and M. Loney, "Analysis of longwall goaf gas drainage trials with surface directional boreholes," International Journal of Coal Geology, vol. 156, pp. 59-73, 2016.

[3] V. Palchik, "Formation of fractured zones in overburden due to longwall mining," Environmental Geology, vol. 44, no. 1, pp. 28-38, 2003.

[4] T. X. Ren, R. Balusu, and C. Claassen, "Computational fluid dynamics modelling of gas flow dynamics in large longwall goaf areas," in Proceedings of 35th Application of Computers and Operations Research in the Minerals Industry Symposium, pp. 603-613, Australia, Wollongong, September 2011.

[5] L. M. Yuan and A. C. Smith, "Numerical study on effects of coal properties on spontaneous heating in long wall gob areas," Fuel, vol. 87, no. 15-16, pp. 3409-3419, 2007.

[6] V. Palchik, "Localization of mining-induced horizontal fractures along rock layer interfaces in overburden: field measurements and prediction," Environmental Geology, vol. 48, no. 1, pp. 68-80, 2005.

[7] M. G. Qian and J. L. Xu, "Study on the "O-shape" circle distribution characteristics of mining induced fractures in overlying strata," Journal of China Coal Society, vol. 23, no. 5, pp. 466-469, 1998, in Chinese.

[8] J. F. Ju and J. L. Xu, "Surface stepped subsidence related to topcoal caving longwall mining of extremely thick coal seam under shallow cover," International Journal of Rock Mechanics and Mining Sciences, vol. 78, no. 5, pp. 27-35, 2015.

[9] J. F. Ju, J. L. Xu, and Z. J. Shan, "Mechanisms of the abnormal first weighting in 'knife handle shaped face' with $7.0 \mathrm{~m}$ high supports," International Journal of Oil Gas and Coal Technology, vol. 9, no. 7, p. 348, 2015.

[10] W. B. Zhu, J. M. Xu, and Y. C. Li, "Mechanism of the dynamic pressure caused by the instability of upper chamber coal pillars in Shendong coalfield, China," Geosciences Journal, vol. 21, no. 5, pp. 729-741, 2017.

[11] G. Xu, J. L. Xu, W. Y. Lv et al., "Lateral boundary prediction of water conducting fracture formed in roof and its application,"
Chinese Journal of Geotechnical Engineering, vol. 32, no. 5, pp. 27-35, 2010.

[12] Q. D. Qu, "Study on the "Three Zones" theory of overlying gas release and migration in response to coal mining and its application," Doctoral dissertation, pp. 79-80, University of Mining and Technology, Xuzhou, China, 2010, in Chinese.

[13] Itasca, UDEC Version 6.0 Universal Distinct Element Code, Itasca Consulting Group, Inc., Minneapolis, MN, USA, 2004.

[14] Z. H. Shui, J. T. Ma, W. Chen, and X. Gao, "The effect of layered double hydroxides on the concrete resistance of chloride-ion penetration," Key Engineering Materials, vol. 509, pp. 99-105, 2012.

[15] W. Qin, J. L. Xu, and G. Z. Hu, "Optimization of abandoned gob methane drainage through well placement selection," Journal of Natural Gas Science and Engineering, vol. 25, pp. 148-158, 2015. 


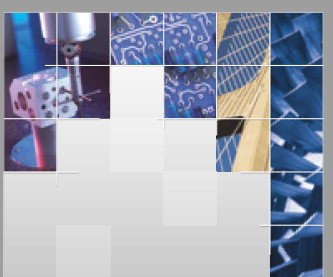

\section{Enfincering}
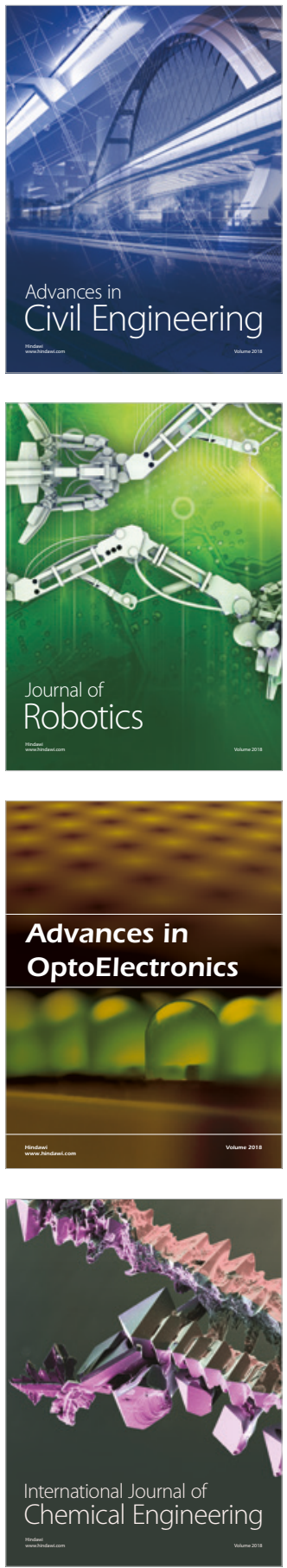

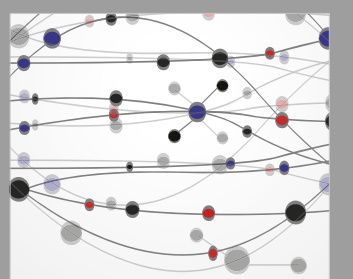

\section{Rotating \\ Machinery}

The Scientific World Journal

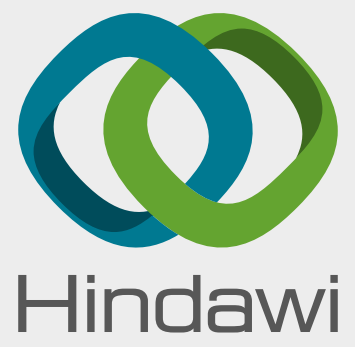

Submit your manuscripts at

www.hindawi.com
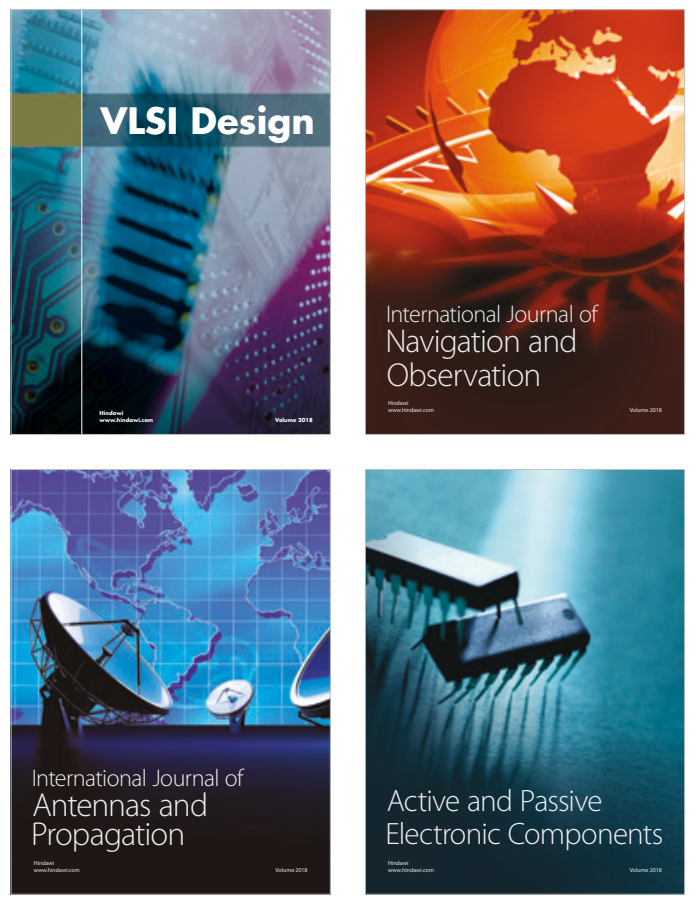
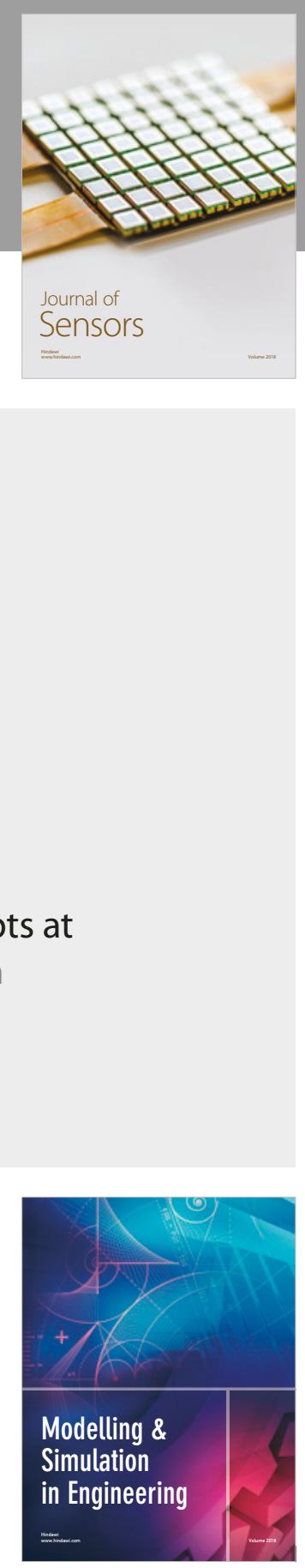

\section{Advances \\ Multimedia}
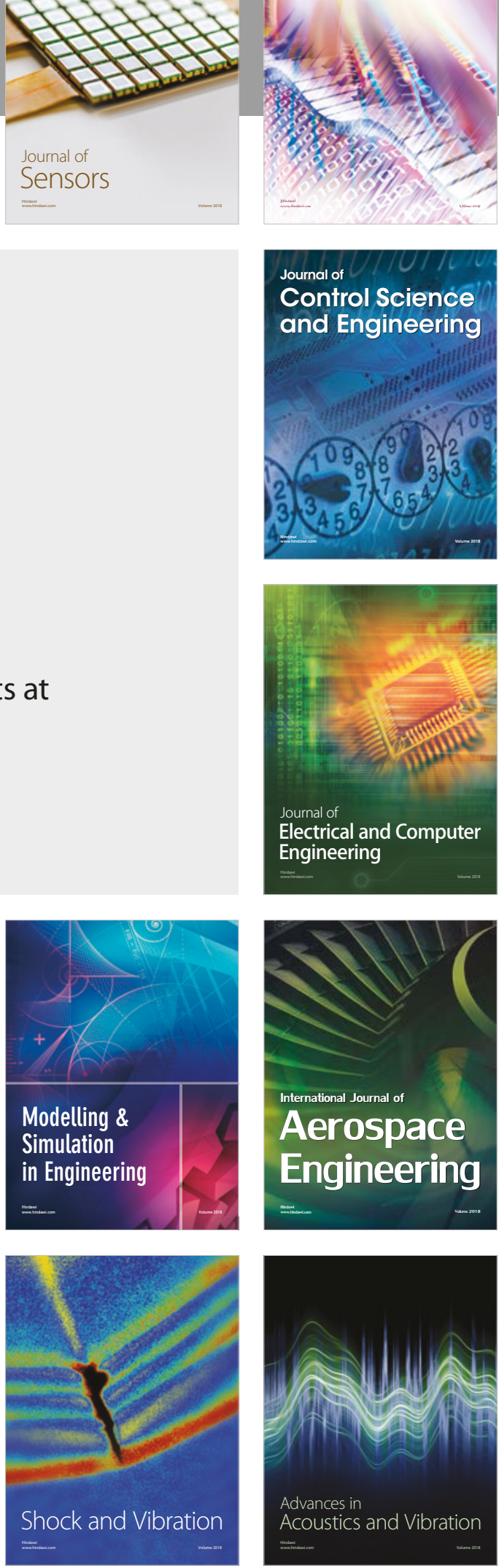